\section{DEADLINE EXTENDED} TO JULY I5, 2012

\section{Important Dates}

July 15,2012 - Abstract Submission Deadline July 30, 2012 - Notification of Acceptance August 31, 2012 - Final Version Submission September 30, 2012 - Early Registration

Calendar at-a-glance

Nov 13 (Tue) Pre-conference Workshops Nov 14 (Wed) CONFERENCE Nov 15 (Thu) Oral, Poster \& Special Sessions
Nov 16 (Fri)

Nov 16 (Fri) 17 (Sat) POST-CONFERENCE WORKSHOPS

\section{General Information}

Congress Theme

Converging Clinical and Engineering Research

Website

www.ICNR2012.org

Venue

Hotel Beatriz

Concilios de Toledo, 45005 Toledo, Spain

Hospital Nacional de Parapléjicos

Finca La Peraleda 4507I Toledo, Spain

\section{Language}

All the contributions and presentations will be prepared in English.

\section{Secretariat}

Pilar Raya,

Bioengineering Group, CSIC

Ctra. Campo Real, km 0.200, La Poveda 28500 Madrid, Spain info@icnr20I2.org

\title{
on Neurorehabilitation
}

\section{Internationa}

Engineering Research

Dear colleagues,

it is our great pleasure to invite you to the first International Conference on Neurorehabilitation, that will take place in Toledo, Spain, from November I4 to 16,2012.

Restoring human motor and cognitive function has been a fascinating research area during the last century. Interfacing the human nervous system with mechatronic systems to restore neuromotor abilities is facing its crucial passage from research to actual clinical reality, enhancing the potentiality of therapists, clinicians and researchers to rehabilitate, diagnose and generate knowledge.

The 2012 International Conference on Neurorehabilitation will bring together researchers and students from the fields of Clinical Rehabilitation, Applied Neurophysiology and Biomedical Engineering in order to promote and encourage this global shift in therapy.

\section{Conference Themes}

Clinical Impact of Technology

Brain-Computer Interface in Rehabilitation

Neuromotor \& Neurosensory modeling and processing

Biomechanics in Rehabilitation

Neural Prostheses in Rehabilitation

Neuro-Robotics in Rehabilitation

Neuromodulation

Others

\section{Contributions}

Extended abstract (2 pages) contributions are welcome. All contributions will be peer reviewed. All accepted contributions will appear in Conference Proceedings. Selected papers will be considered for publication in Specia Issues in International Journals (e.g. JNER, JACCES).

The conference will be preceded and followed by Workshops, and interspearsed by Special Sessions and tematic Round Tables. Supporting materials for Workshops, Special Sessions and Round Tables will also be published in the Conference Proceedings.

IIIE JOURNAL OF NEUROENGINEERING AND REHABILITATION
Keynote Speakers Prof. Grégoire Courtine EPFL, Zurich

Prof. M. Chiara Carrozza Scuola Superiore Sant'Anna, Pisa

Prof. Donatella Mattia IRCCS Santa Lucia, Rome Prof. Mathias Bähr University of Göttingen Medical School Prof. Jane Burridge
University of Southampton

\section{NEW! Student Competition}

Paper Competition for undergraduate and graduate students is now open!

All contributions will be peer reviewed. Seleced finalists will present their work with Posters and Oral presentations.

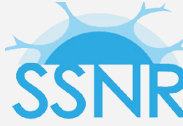

The winner will be awarded with a free inscription to the 2013 Summer School on Neurorehabilitation (for more information about Summer School please visit the website of 2012 edition: www.SSNR20I2.org).
Conference Chair

Prof. José L. Pons

Conference Co-Chairs

Prof. Marco Molinari

Dr. Ángel Gil-Agudo

\section{Steering Committee}

Metin Akay, U. of Houston, USA, Chair José L. Pons, CSIC, Spain

Silvestro Micera, SSUP Sant'Anna, Pisa, Italy Dario Farina, UMG-GOE, Germany José Carmena, U. of California, Berkeley Paolo Bonato, Spaulding Hospital, USA

Conference Committee José L. Pons, Chair Marco Molinari, Co-Chair Angel Gil-Agudo, Co-Chair Juanma Belda Eduardo Fernández Ales Holobar Winnie Jensen Thierry Keller Rui Loureiro Silvestro Micera José del R. Millán Vito Monaco Juan C. Moreno erdinando Mussa-lvaldi

Dejan Popovic

Richard Reilly Eduardo Rocon

Shingo Shimoda

Thomas Sinkjær

Thomas Stieglitz Toshiyo Tamura

Julian Scott Taylor Nicola Vitello

Organization Committee Marta Pajaro, Publications Chair publications@icnr2012.org Diego Torricelli, Workshops Chair workshops@icnr20/2.org

Rafael Raya, Exhibitions Chair exhibitions@icnr20/2.org 

Engineering Research

Nov $14-16,2012$

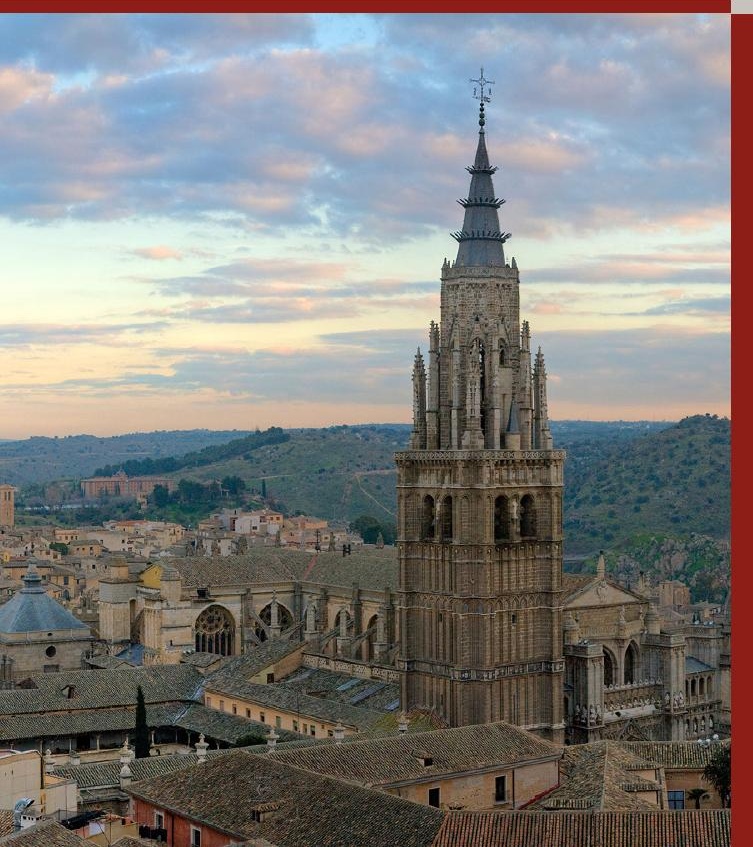

\section{About Toledo}

The city of Toledo, declared a World Heritage Site by UNESCO in 1986, is located on a rocky headland, bordered by the river Tajo in the very heart of Spain, just 70 kilometres from the capital, Madrid. Considered by many to be a "Second Rome", Toledo is still very much a unique city. Unique in its details, history, culture and charm. Three cultures from three single-faith religions - Muslim, Hebrew and Christian - left their imprints on this sad rock and cradle of civilisations - as Cervantes wrote - embracing the Tajo, witness to the mark of all the peoples of the lberian Peninsula.

Churches, synagogues, mosques, convents, city walls, bridges, towers and an endless amount of cultural and artistic possibilities held in their buildings make Toledo a museum waiting to be discovered. Made to be walked along their long slopes and to be seen on the horizon, there are a large number of monuments in Toledo, surrounded by unforgettable spots and places that awaken sensations in the eyes of those who visit and those who have the good fortune to live there.
International

Conference

\section{on Neurorehabilitation}

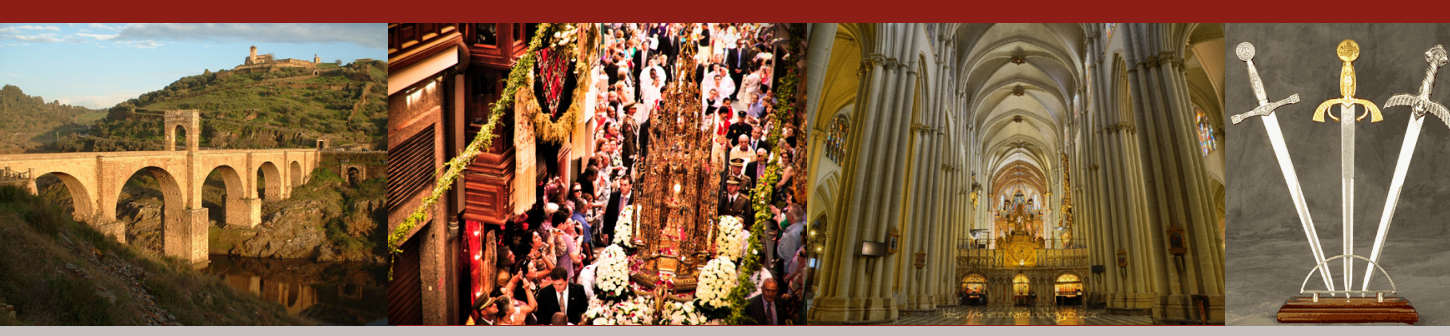

Toledo, Spain

\section{Organizers:}

\section{CSIC}

Spanish National Research Council

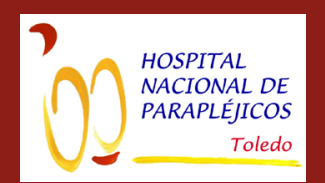

Paraplegic National Hospital,Toledo
Technical Sponsors:

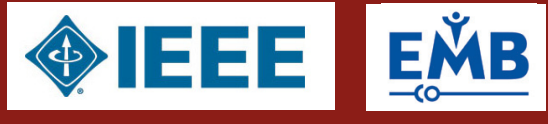

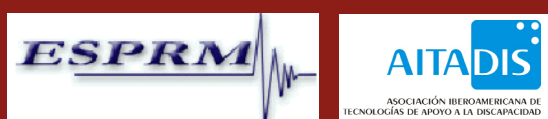

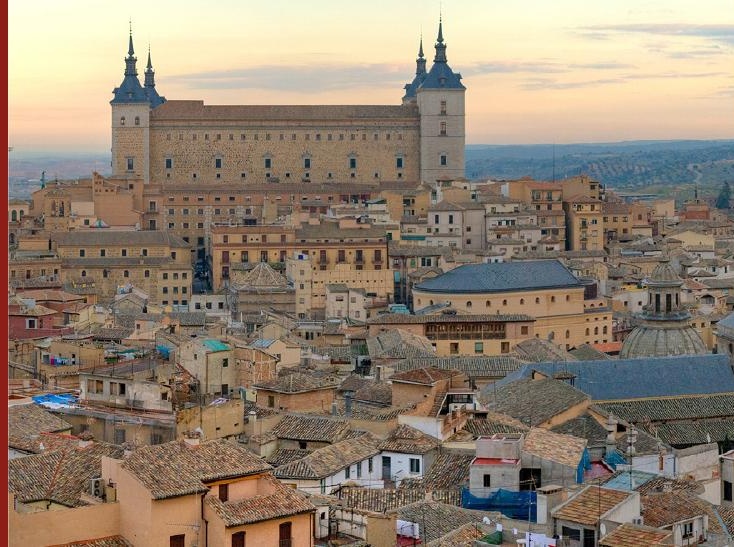

